\title{
Innovative ways of design education developing at the university
}

\author{
Vera Shepilova ${ }^{1,}{ }^{*}$ and Marina Golovanova ${ }^{1}$ \\ ${ }^{1}$ Don State Technical University, 344003, pl. Gagarina, 1, Rostov-on-Don, Russia
}

\begin{abstract}
Design education is rapidly developing in unity with formation and strengthening of theoretical and methodological design basis. Changing requirements for the modern educational system provokes the search for innovative ways of development. Rapid introduction of distance education has made it possible to test experimental forms and methods of teaching design students. As a result of processing the experimental data, outdated models of the organization of the educational process, the lack of flexibility and variability of curricula and work programs of disciplines were revealed. It became necessary to adjust the educational process, taking into account modern mental characteristics of students, their levels of motivation, system of values and ideas about the profession of a designer, taking into account dynamic development of existing design directions and emergence of new specific branches. These factors determine the creation of a methodological model built into the context of design education, which should have such qualities as flexibility and adaptability to changes in the external environment. Implementation of flexible adaptive design teaching model becomes a source of innovative changes in this very external environment. To build a methodological system, the following methodological approaches were used: cognitive, reflexive, eutagogic, synergetic, personality-activity, heuristic-algorithmic, recursive-design.
\end{abstract}

\section{Introduction}

\subsection{Relevance}

Since the beginning of the second millennium, there is a need to put into practice innovative approaches to design education. This problem has been under discussion for over 20 years thanks to the emerging and actively developing design theory and methodology. Design education, like design theory, is in the making. The search for optimal regulators of achieving pedagogical goals and the creation of training systems that ensure the formation of students' competencies necessary in the professional field of design determines the relevance of research.

In Russia, the problems of design education are affected by such scientists as E.N. Koveshnikova, N.A. Koveshnikova, N. S. Mamyrina, V. M. Miroshnikova, L.V. Shokorova,

\footnotetext{
* Corresponding author: verashep@mail.ru
} 
K.V. Esekkuev, Researchers analyze various design schools, describe existing contradictions and highlight problem areas, present possible ways for the development of modern design education, recognize the need for its changes, but do not put forward specific proposals for the implementation of innovations, and also does not describe the experience of applying these innovations in practice.

The processes associated with the rapid introduction of distance education and the transition to new forms of education force to look for innovative forms and methods of teaching design through personal experience, to explore areas in need of reform in order to make adjustments and increase the effectiveness of the educational process.

\subsection{Problematic areas of design education}

Research based on a comparative analysis of teaching work in real and remote modes and the study of scientific domestic and foreign experience allow us to identify problem areas of design education that are subject to change.

The introduction of distance learning revealed outdated forms of organization of the educational process, the lack of flexibility and variability of curricula and work programs of disciplines. In the process of experimental observation, it was possible to identify several problem areas.

1. Obsolescence of the system of values and guidelines, changes in the psychological characteristics of students, motivation. Inappropriateness of education to the actual needs of society [1-2].

2. Obsolete learning content:

- the need to take into account the annual changes in cultural patterns and aesthetic ideals due to fashionable transformations when demonstrating design objects to students;

- the need for the teacher to master the skills of adapting basic scientific provisions to constantly changing views of values from outside;

- lack of elective disciplines in connection with the individual aspirations of the student;

- the need to take into account the individual trajectory of development and mastering of the material by students;

3. Outdated teaching methods:

- orientation of teaching methods to memorizing and reproducing information and work according to specified algorithms;

- the formation of a handicraft type of consciousness in students, which requires a longterm refinement of a narrow set of professional skills and abilities.

4. Weak technical organization of distance education:

- insufficient equipment of teachers and students with the technical equipment necessary for online interaction;

- the unwillingness of a part of the contingent of teachers and students to use the technical means of distance technologies;

- the complexity of adapting the content of curriculum programs of creative disciplines to the remote communication format;

- increase in the cost of time resources due to an individual approach when working in a group;

- difficulties in monitoring progress and certification.

\subsection{Hypothesis}

Having considered the relevance and familiarized with the problem areas, it is possible to formulate a hypothesis assuming that the presence of a theoretical model of an adaptive methodological system of teaching in design education, which implements innovative ways 
of developing education in the field of design and the formation of a theoretical model of a methodological system, will help resolve the contradictions that arise as a result. dynamic changes in education, society and design.

Further, it is necessary to describe the components of the theoretical model of the adaptive methodological system of design education.

\subsection{Methodological approaches}

To build a methodological system, the following methodological approaches were used: andragogical, cognitive, reflexive, eutagogic, synergetic, personality-activity, heuristicalgorithmic, recursive-design [3-5].

\section{Description of conditions}

Based on the analysis of problem areas and in accordance with the ideas about the design education of the future, it is necessary to implement innovative ways of development within the framework of the components of the theoretical model of the methodological system.

All the components of the system require updating and rethinking. These are, first, the components that make up the basis of the model: target, motivational, content, and procedural and activity, organizational and managerial, performance and evaluation.

This process is due to the need to make adjustments to the construction of the educational process, taking into account changes in psychological characteristics, motivation, value systems and ideas of students about the profession of a designer, as well as taking into account the dynamic development of existing design directions and the emergence of new specific branches in them, reflecting the needs of modern society [6].

The transformation of the model of the methodological system is also necessary in order to adapt it to the conditions of distance design education, which ensures the effectiveness of the implementation of the educational program, the formation of competencies characteristic of traditional full-time education and the educational component.

Another important factor in the creation of this model was the focus of education on the formation of a new way of thinking of an integrative and inventive nature, the ability to think quickly, analyze, synthesize information, generate ideas, present tasks holistically and design ways to solve them; as well as taking into account the modern working conditions of a designer with a high cost of time resources, competition and a high level of development of a variety of technologies [7].

\section{Model description}

Thus, it is possible to make a description of the theoretical model of the adaptive methodological system of design education. 


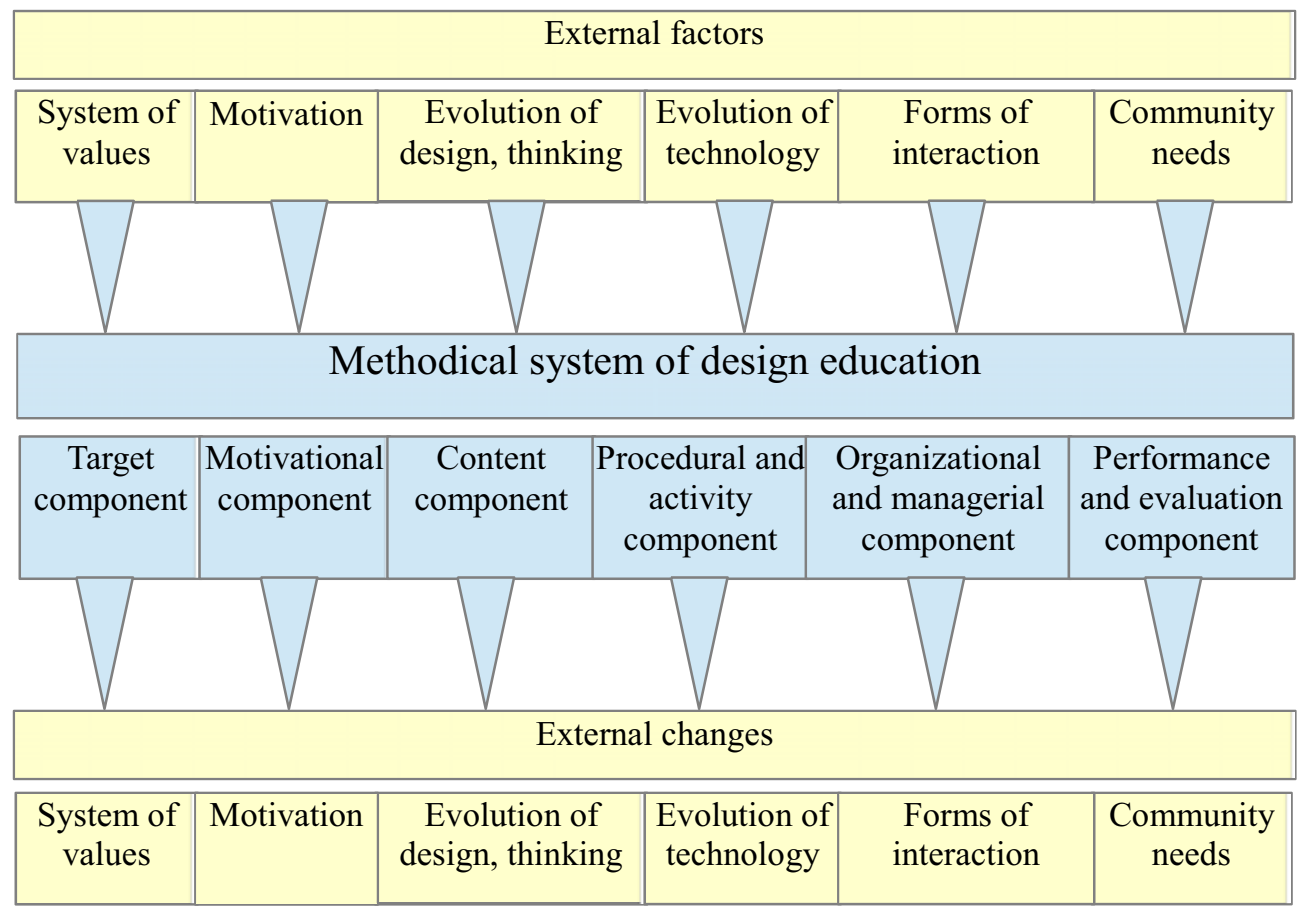

Fig. 1. Theoretical model of the adaptive methodological system of design education.

Thus, it is possible to define the description of the theoretical model of the adaptive methodological system of design education.

The adaptability of a model is determined by its ability to reflect the dynamic properties of external factors of a modern changing society, such as: value system, motivation, design evolution, technology evolution, new forms of interaction between participants in the communication process and the needs of society. In turn, the implementation of an adaptive design learning model contributes to the emergence of designers, transmitting to society their new understanding of the system components. Thus, the cyclical nature of constant updating of the model is provided [8]. All the components of the model are closely related and interact with each other.

Consider the content of the model based on the characteristics of the impact of external factors.

\subsection{Target component}

The target component is formed under the influence of the environment and affects the entire system of design education. The basis of the target component is the value system formed in society for a given period of time. An increased interest in design in society, an increase in the demand for designers, an increasing complexity of design tasks, a growing area of application of design, the emergence of new directions related to design, the emergence of new directions requires changes in all components of the methodological system model [9].

\subsection{Motivational component}

The motivational component is determined by the attitude to the profession of designer and 
design in general, ideas about future professional activities. The completeness of these ideas, in combination with personal qualities, determines the likelihood of adaptation to design education, development within the framework of the educational process, the ability to go through its mandatory stages and be realized professionally. Therefore, motivation is highlighted as a component of the methodological system in view of the importance of its meaning. It is not uncommon for future designers to choose this profession because of fashion, or the desire to find a job easily and pursue exclusively personal goals. Some are simply interested in obtaining higher education without positioning themselves in the profession. The idea of the future is very vague and vague, graduates of high school do not perceive design as a rational activity with a lot of practice, but see it as an exclusively creative activity that does not have clear criteria. Many apathetic and rather infantile students follow the instructions of their parents. A fundamentally important task is the formation, already in the initial course of training, of sustainable motivation aimed at understanding the global significance of design in shaping the human environment and influencing people's consciousness.

\subsection{Content component}

The content component of modern design education is based on the constant evolution of design. An important factor in the fundamental design of education is the training of designers who have modern competencies and are able to develop and work in the context of the dynamically changing needs of society. For example, now the world community is more and more concerned about the growing trends towards the transformation of the designer's thinking, who must have a special quality, a unique scaling property, determined, on the one hand, by an understanding of the globality of design, and on the other hand, by the possibility of immersion in a highly specialized design problem to solve specific applied tasks at the level of product design, communication design or visual design [10]. Such a content component of the system influences the formation of a special understanding of design problems: very specific and at the same time embedded in the general global design field; and as a consequence, a change in attitude towards the process, the organization of design activities, the choice of algorithms for solving the problem, and the result.

The formation of such an understanding will be facilitated by the theory and practice of teaching, experimental, inventive activity aimed at solving design problems not only of various scales, but also from various fields. Since scaling down a design problem requires a deep immersion of the designer in a specific area of expertise or a combination of areas.

Due to the innumerable number of such areas and their combinations, it is not possible to prepare a designer to solve narrow-profile tasks in various fields of knowledge or at their intersection in full, but it is possible to create a certain experience of such work, paying special attention to the interpenetration of disciplines [11]. One example is the setting of educational tasks based on the interpenetration of design and the field of literature and foreign languages, enriching the imaginative, artistic vision of the designer, allowing to expand the scope of knowledge, using translations and epithets from different languages. This approach can be especially important for designers who create design objects aimed at communication.

In connection with the penetration of design into all spheres of human life, it is necessary to train highly specialized scientific personnel, each of which could develop specific approaches that are useful in problem areas of human life [12].

The emergence of new branches of design development, new areas of knowledge and their combinations leads to the fact that it becomes more and more difficult to determine to single out a specific problem of design-engineering, often it is a complex of hard-to-grasp 
problems, they are rarely simple and clearly defined. The designer is required to be flexible, sensitive to problems on an almost intangible, mental level. And the tasks of a designer can be multifaceted - somewhere he acts as a strategist, somewhere a meticulous designer, somewhere the developer of the main idea, depending on the tasks. Therefore, the emphasis is shifting from the design of the subject environment to the design of the consumer's lifestyle in its various spheres of life - work, training, organization of leisure time, etc., in a complex, acting within the framework of understanding a single system of understanding the structure of people's life, their values. All these features should be reflected in the content of design education.

In connection with the formed scientific base and systematic design, it is necessary to establish a connection between university programs and research activities aimed at solving urgent design problems. Use university platforms to build research skills in this area. This should lead to the development of academic undergraduate programs, along with applied programs [13].

Solving complex problems at the junction of areas of knowledge of various scales should not be the final design point. An important part of the educational content should be the search for solutions that would be easy to manufacture and could be implemented as prototypes or models already in practical classes at the university. This leads to the search for innovative technologies in design through research and experimental activities, discoveries, the search for innovations already at the stage of education [14]. An important achievement in the implementation of such educational content is the experience of creating a unique ready-made sample of a design product, as well as the connection between theoretical and practical design in the material. Interdisciplinary communication in professional practice has become the norm, but it is still poorly developed in education, each discipline deals with a separate area and does not overlap with others. Thus, the content of design education requires more variability in the learning process, because it is difficult to establish the content of the training course suitable for a wide range of design tasks.

The solution to the issue of interdisciplinary ties and a new progressive way of developing design education can be the creation of educational interdisciplinary platforms that are part of the organizational and managerial component of the considered model of the methodological system.

\subsection{Procedural and activity component}

The procedural-activity component is implemented in close connection with the specifics of the content of design education and based on the evolution of design technologies that require specific forms of design activity. This component is implemented in the interaction of students with each other, with teachers, with new technologies. The procedural component consists of pedagogical conditions, methods and teaching aids, which are also undergoing changes. First, it is an orientation towards self-study in the field of digital technologies, because the area of interaction with digital devices in modern generations has been formed since childhood. This eliminates the need in the learning process to master the simplest activities to master the simplest basic functions, it is necessary to focus on the development of a wide range of different digital products [15].

The focus on self-study in the field of technology is associated with andragogical and personality-oriented, eutagogic approaches that determine the attitude towards students as responsible people who have made an informed choice and strive to realize their potential. Professional practice begins from the moment of professional training and lasts all professional activities throughout life. Such approaches define a new system of relations, a change in roles in design education. The teacher is no longer a master imparting knowledge 
to the student. The teacher becomes a co-creator, like-minded person, a participant in the creative process. The teacher is responsible for the learning process, and the learning outcome is projected by the student, depending on his conscious ideas about future professional activities. This approach provokes changes in the guidelines of design education for intellectual flexibility and concern for human values [16].

\subsection{Organizational and managerial component}

The organizational and management component determines the organizational forms of design training. This theoretical model of the methodological system should realize the possibility of teaching both in traditional forms and taking into account the possibility of switching to distance learning at any stage of the educational process. Distance learning is fully connected with the quality management of the educational process at the stages of training: lesson planning, educational research work, process control, evaluation of results. An important condition for the successful transition and functioning of distance learning is the reflection of students' activities, strengthening of feedback, a variety of technologies that ensure variability of use and compliance with the needs of all participants in the process. Distance learning allows the system to acquire flexibility [17].

The creation of educational platforms for teaching design is an urgent need in modern conditions. Such educational platforms make it possible to provide access to educational design resources for a significantly larger number of students in comparison with traditional forms of education, allow solving the issues of reducing the burden on teachers with an increasing interest in design and design education, and carrying out training in the framework of andragogical and student-centered approaches, correspond to the forms of remote communication using information digital technologies that are in demand in society and continue to develop [18].

\subsection{Performance and evaluation component}

The performance-evaluating component reflects the requirements for the quality of design training defined by the standard and regulatory documents. Also, the productive-evaluative component is determined by the needs of society in design products, and professional designers who are able not only to express themselves in design activities, offering the results of their fantasies, but to solve urgent problems of modern society through design opportunities, improve people's comfort, demonstrate a high cultural level, strive for the development of civilization, design the future design system.

The theoretical model is a methodological guideline for the construction and implementation of the methodological system of design education at the university, to promote the training of designers, whose professional level will meet the needs of a dynamically changing society.

\section{Results and conclusions}

1. A comparative analysis of teaching work in real and remote modes and the study of scientific foreign experience made it possible to identify problem areas of design education that are subject to change.

2. A hypothesis was formed according to which a theoretical model of an adaptive methodological system can serve as the basis for resolving contradictions arising because of dynamic changes in education, society and design.

3. Based on the analysis of problem areas and in accordance with the ideas about the 
design education of the future, it was decided to formulate innovative ways of development within the framework of the components of the theoretical model of the methodological system.

4. A description of the components of the theoretical model of the adaptive methodological system of design education has been compiled: target, content, procedural and activity, organizational and managerial, productive and evaluative, which require rethinking and updating. Highlighted a new component of the system motivational, justified its necessity.

5. The adaptability of the methodological system, the connection and influence of external factors on the components of the model, and the influence of its implementation on changes in society are revealed. Thus, ensuring the cyclical nature of constant updating of the model.

6. The content of all components of the system is revealed, the necessity and directions of their transformations are substantiated. There is a close relationship and mutual influence of the components on each other.

7. The theoretical model includes the transformation of the components associated with overcoming difficulties based on the analysis of practical teaching activities in the studied area and the world research experience in the development of design education, will help resolve the contradictions that arise as a result of dynamic changes in education, society and design.

In conclusion, it must be said that the formed model is an objective embodiment of the solution of urgent design problems; it needs further research from the point of view of its subjective interactions in the context of modern changes in society. Therefore, for example, what are the subjective interactions within the framework of this model of the teacher and the student, how the potential of the educational system depends on the personal and professional characteristics of the former and the individual abilities and psychological readiness of the latter.

\section{References}

1. N.Y. Zakharova, I.V. Protopopova, V.A. Shepilova, Yu.G. Likhovid, IOP Conference Series: Materials Science and Engineering 698, 033018 (2019) doi. 10.1088/1757899X/698/3/033018

2. Boxin Xiao, International Conference on Environment and Water Resources Engineering, E3S Web of Conferences 179, $02035 \quad$ (2020) doi.org/10.1051/e3sconf/202017902035

3. Mieke van der Bijl-Brouwer, Bridget Malcolm, She Ji: The Journal of Design, Economics, and Innovation 6, 386-407 (2020) doi.org/10.1016/j.sheji.2020.06.001

4. M.J. Baker, F. Détienne, C. Mougenot, T. Corvin, M. Pennington, Learning, Culture and Social Interaction 26, 100436 (2020) doi.org/10.1016/j.lcsi.2020.100436

5. E. Barba, She Ji, The Journal of Design, Economics, and Innovation 5, 147-162 (2019) doi.org/10.1016/j.sheji.2019.04.003

6. J. Frascara, She Ji, The Journal of Design, Economics, and Innovation 6, 106-117 (2020) doi.org/10.1016/j.sheji.2019.12.003

7. T.B. Heinis, I. Goller, M. Meboldt, Procedia CIRP 50, 759-764 (2016) doi.org/10.1016/j.procir.2016.04.120

8. F. Loch, M. Fahimipirehgalin, J.N. Czerniak, A. Mertens, V. Villani, L. Sabattini, C. Fantuzzi, B. Vogel-Heuser, IFAC-PapersOnLine 51, 335-340 (2019) doi.org/10.1016/j.ifacol.2019.01.023 
9. J. Redström, She Ji, The Journal of Design, Economics, and Innovation 6, 83-100 (2020) doi.org/10.1016/j.sheji.2020.02.001

10. J. Myerson, She Ji, The Journal of Design, Economics, and Innovation 4, 288-299 (2016) doi.org/10.1016/j.sheji.2017.06.001

11. J. Cezzar, She Ji, The Journal of Design, Economics, and Innovation 6, 213-227 (2020) doi.org/10.1016/j.sheji.2020.05.002

12. M.W. Meyer, D. Norman, She Ji, The Journal of Design, Economics, and Innovation 6, 13-49 (2020) doi.org/10.1016/j.sheji.2019.12.002

13. А. Sarwak, P.T. Fraser, She Ji, The Journal of Design, Economics, and Innovation 4, 343-355 (2020) doi.org/10.1016/j.sheji.2019.11.002

14. E. Voûte, P.J. Stappers, E. Giaccardi, S. Mooij, A. van Boeijen, She Ji, The Journal of $\begin{array}{llll}\text { Design, } \text { Economics, and Innovation } & \text { 6, 50-66 }\end{array}$ doi.org/10.1016/j.sheji.2019.12.001

15. A.-M. Nortvig, A. Kristine, P. H. Helsinghof, B. Brænder, Computers \& Education 159, 104020 (2020) doi.org/10.1016/j.compedu.2020.104020

16. S. Pontis, K. van der Waarde, She Ji, The Journal of Design, Economics, and Innovation 6, 228-253 (2020) doi.org/10.1016/j.sheji.2020.05.005

17. K. Friedman, She Ji, The Journal of Design, Economics, and Innovation 5, 1-4 (2019) doi.org/10.1016/j.sheji.2019.02.002

18. E. Heyden, J.K. Kuchenhof, E. Greve, D. Krause, Procedia CIRP 91, 553-558 (2020) doi.org/10.1016/j.procir.2020.02.213 